\title{
An Investigation of Selection Criteria for Admission to an Ontario University
}

\author{
GORDON POLLOCK, RICHARD J. BOWMAN, PAUL GENDREAU, AND LORNA \\ GENDREAU*
}

\begin{abstract}
The study investigated the effectiveness of five methods of university admission criteria in relation to academic results achieved after one year of university study. The admission criteria used were open admission, interview, teacher recommendations, Grade 13 academic achievement and SACU test scores. In addition these procedures were compared with a traditional method of admission at the university where the study was carried out. The characteristics of the admission groups were not significantly related to geographical distribution, sex distribution, government financial assistance, and attitude and personality questionnaire data. These characteristics were no different for these groups than the traditional method of selection and there was no significant difference between groups as to final first year grade point average or academic penalty i.e., probations and rustications. The open admissions group compared favourably on these latter variables with other admissions groups and particularly with the university's traditional method of admission.
\end{abstract}

Since the abolition of the Department of Education external examinations in the Province of Ontario, there has been no proven standard measuring device for use in the selection of applications for admission to university. This set of examinations has been replaced by various types of assessment in each school with the result that there are literally as many means of assessment as there are secondary schools in the Province. In order to contend with this situation, universities have continued to assume a relationship between Grade 13 and first year university achievement based on the old correlations between Grade 13 and first year university achievement. Some university admissions committees have attempted to augment their selection procedures with objective tests. The Service for Admission to Colleges and Universities (SACU) was a major attempt to provide such test results on a national basis.

What of the validity of these procedures? Outside of limited and unpublished, "within house" projects of selection of applicants (i.e., Boronkay, 1972) the only comprehensive

*Mr. Pollock and Mr. Bowman are Associate Registrar and Director of Admissions respectively at Trent University. Paul Gendreau is Chief Psychologist, Eastern Region, Ontario Ministry of Correctional Services, and Honorary Research Associate, St. Patrick's College, Carleton University. Lorna Gendreau is Supervising Psychologist, Brockville Psychiatric Hospital. 
study in this area was the Atkinson Study of Utilization of Student Resourses (19571967) carried out in an era when a great deal more structure of curriculum prevailed in the Province and a universal set of Grade 13 examinations was administered. The results at that time indicated Grade 13 to be the best predictor, that is, if one considers the highest predictions accounting for $25 \%$ of the variance (primarily for students in Arts faculties) as being adequate. Indeed, predictive validities of criteria for university academic success are often much lower.

Today, the alternatives for university admissions officers are not attractive, predictive validities under the optimal circumstances are mediocre and the best predictor, Grade 13 , may at some point become inoperative. Increasingly, administrators in Ontario universities find themselves in the quandary of having admitted some students who do not appear to be profiting from university instruction and do not seem suited to this type of education. A further complication is that universities know full well that because of the arbitrariness of their selection procedures, they have excluded a goodly percentage of students who may not only profit from university instruction, but who, by their exposure to university teaching, may offer a great deal to the community. In view of these circumstances, it seems appropriate at this time when substantive changes are under way in the secondary school system, to provide not only updated validities of the traditional methods of selection of applicants for admission, but to critically assess alternate criteria which in themselves may prove to be more meaningful and appropriate than those which are now in use.

More specifically, this study attempted to assess the predictive validity of the standard measure, Grade 13 academic achievement. While not as widely used, SACU test scores, teacher recommendations and personal interviews have been sometimes employed by admissions offices. Selection in this study employed each of these criteria. The controversial concept of open admissions, long considered to be improper for Ontario universities, was also used as a selection device. It could be argued that this device is the most economical and it avoids one of the common human cost errors made by admission officers, i.e., rejecting applicants who would profit from university training. The traditional argument against open admissions has been that too many inferior students would be admitted resulting in either a lowering of academic standards or an unacceptably high failure rate. The present study employed an additional sixth admissions category utilizing the normal procedure followed by the Registrar's Office in the university where the study was based.

Also obtained were measures of personal satisfaction with university life. The study measured attitudes towards education, politics, societal structures, aesthetic concerns and personality. These measures were correlated with admission criteria and academic standing. In addition, characteristics of "drop outs" were examined.

\section{METHOD}

\section{Selection of Subjects}

Two thousand, five hundred and ninety-three students then enrolled in a full Grade 13 program for the year 1971-72 applied for admission to Trent University for the aca- 
demic year 1972-73. As applications arrived, and before any processing was done each $S$ (student) was assigned a code number signifying membership in one of five admission groups -1 . Open admissions, 2. Interview, 3. Teacher recommendation, 4. Grade 13 academic achievement, and 5. SACU tests. This assignment was done by clerical staff in the Registrar's Office who were unaware of the nature of the relationship between the code number and the selection criteria.

Subjects within each group were selected as follows:

Open Admissions: From the $503 \mathrm{Ss}$ (students) assigned to this group, 375 were randomly selected and offered admission to the university. One hundred and three accepted the offer while 93 actually registered in September 1972.

Interview: From the group $498 \mathrm{~S}$ s assigned to the interview category 350 were interviewed by a trained interviewer. The areas covered in the in-depth structured interview were:

a. An indication that some independent thought had gone into plans for university.

b. Involvement in extra-curricular activities and work.

c. Interest in things outside the academic sphere - reading, news, etc.

d. Extensive reading in related and other areas and discrimination in type of T.V. programs selected.

e. Positive attitude to school and learning (interest).

f. Reasonable study and essay writing techniques.

g. Knowledge of the University and its teaching system.

h. Self awareness.

The interview was scored on an Excellent, Above Average, Average, or Poor rating based on the student's ability to communicate the above information logically and reasonably. In order to qualify, a rating of Average was needed. Two hundred and fifty-six $S$ s were offered admission. Of these, 102 accepted and 96 actually registered. Teacher Recommendations: Questionnaires were sent to the school in which each of the $496 \mathrm{Ss}$ in this group was enrolled with the request that they be filled out by teachers knowing the student and returned to the researchers. The questionnaires aimed at assessing the following attributes of the $S \mathrm{~s}$ : 1 . organization of thought and written assignments, 2. active participation in academic and extra-curricular activities, 3. responsibility and cooperation in academic and school life in general, 4. originality in school work, 5. ability to work consistently over a period of time, and, 6. teacher's conception of strengths and weaknesses in regard to university success.

In order to be offered admission in this category each $S$ needed a minimum of three questionnaires (each by a different teacher) returned on his behalf. Each question was quantified on a rating scale basis. Some questions were more heavily weighted than others. In summary, an arbitrary cut-off score of 119 was used to accept an applicant. Two hundred and eighty-three $S$ s qualified, 79 accepted and 74 registered.

Grade 13 Academic Achievement: From the original $498 \mathrm{Ss}$ assigned to this group 377 applicants who had an interim Grade 13 average equal to or greater than $60 \%$ and who had no failures in the six credits prescribed for university admission were offered admission. One hundred and ten accepted the offer and 105 registered. 
$S A C U$ Tests: Five hundred and thirteen $S$ s in this group had written both the Verbal and Mathematical Sections of the C.S.A.T. test administered by SACU. Scores of 401 in the C.S.A.T. (V) and 326 in the C.S.A.T. (M) were used as the minimum admission requirement for this group. Of the 371 applicants offered admission, 98 accepted and 91 actually registered.

Traditional Admission: The sixth category was composed of those applicants who were not admitted to any of the above five groups. It consisted of applicants who had achieved the level required for Early Admission based upon the interim Grade 13 results, and those applicants who raised their Grade 13 averages at the time of the final school examinations to meet the normal admission requirements of university (60\% on six credits, no failures in these credits). These students had not necessarily been rejected from the other groups, but may have not been at school when our interviewer was present, had not written SACU tests, had incomplete teacher questionnaire forms, or had not been randomly assigned to the open admission category. Three hundred and thirty-six such students were offered admission, and 103 accepted the offer. Ninety-nine students actually registered at the university.

All students from groups 1, 2, 3, or 5 who were offered admission but who did not meet the normal academic admission criteria for the university were sent a letter stating that they did not meet the normal requirements but that other criteria were also being used in selection. These students who otherwise would not have received admission form a sub-group of project admissions (P.A.'s).

Throughout the course of this study no student or faculty member was told the basis on which any student had been offered admission.

\section{Attitude Measurement}

To determine student attitudes towards education, politics, societal structure and aesthetic concerns the following attitude questionnaires were adopted from Shaw and Wright (1968): Attitude toward education: Exhibit 3-14; 6-2; Education scale: Exhibit 6-1; Semantic distance questionnaire: Exhibit 10-1; Tulane factors of liberationconservatism attitude values profile: Exhibit 7-6. The attitude measurement questionnaires were mailed in mid-August to the home address of all students who had accepted the university's offer of admission. Students who failed to return the questionnaire at or prior to registration were asked to fill one out as they registered.

\section{Interview, Withdrawal Information and Personality Inventory}

Two inter-connected concerns which the research group tried to assess involved satisfaction with the university and adjustment to the university environment. A random sample was selected from each admission group and interviewed between January and April of the academic year. The interview was conducted by two trained interviewers and covered areas related to personal satisfaction with the university in general, with courses, with teaching methods, with their social life, and with finances. At the conclusion of the personal interview the Adjective Check List (Gough \& Heilbrun, 1965), a measure of personal adjustment, was administered to consenting students. A total of 277 students were interviewed, 46 from group 3, 48 from group 2, 47 from group 3 , 48 from group 4,47 from group 5 , and 41 from group 6 . 
As part of the withdrawal procedure full-time students who left the university were asked to complete a questionnaire. This questionnaire was designed to elicit information about the student's satisfaction with his university experience and factors influencing his decision to withdraw.

\section{Measures of Academic Success}

Two measures of academic success were obtained for each student who completed a full academic year, i.e., who registered and did not officially withdraw or drop to parttime status.

A grade point average (GPA) was calculated by assigning a numerical equivalent to the university's letter grades. These were: $\mathrm{A}=4.0, \mathrm{~B}+=3.5, \mathrm{~B}=3.0, \mathrm{C}=2.0, \mathrm{D}=1.0$, $F=0$. The GPA equalled the mean of the scores for the courses in which the student was enrolled. For students who had officially dropped from the normal course load of five to four courses, the average was based on only four courses.

The second measure a categorical success description (C.S.D.) consists of three categories. First of these, clear success, comprised all students who had completed their year with a GPA of better than 1.4. The probationary success category contained those students, mainly with GPA's between 1.2 and 0.75 whom the university's Academic Standing Committee felt had met the minimum requirements of the university and would be permitted to return the following academic year but required a warning about their overall standing. The rustication category included those students whose academic performance was such that the Academic Standing Committee required them to withdraw from the university for one academic year, and whose grade point average was usually less than 0.75 . These figures are not restrictive. There were a few exceptions who had grade point averages that did not match their classification. These particular decisions were made by the Academic Standing Committee of the university.

It is important to note that the Research Group was not involved in the deliberations of the Academic Standing Committee. No member of that committee nor any member of the teaching staff knew the basis of admission of any individual whose grades were under review. The criteria used to measure academic success were the same used by the university itself to evaluate its students.

\section{Acceptance Rates}

\section{RESULTS}

The percentage of students offered admission who actually registered was $24.9 \%$ for group $1,36.7 \%$ for group $2,26.1 \%$ for group $3,28.1 \%$ for group $4,24.5 \%$ for group 5 , and $29.4 \%$ for group 6 .

\section{Characteristics of the Class}

To assess the effect of the selection procedure on the composition of the class, the 1972-73 class was compared with first year classes of the five previous years.

\section{Geographical Distribution}

The geographical distribution of the experimental class was indistinguishable from those of previous years. 


\section{Academic Standing}

Table 1 shows the distribution of the Grade 13 grades. As can be seen with the exception of the small groups of $S$ s admitted by the project falling in the $49-59 \%$ category, the marks distribution of the $1972-73$ class was similar to that of previous years.

Table 1

Academic Standing of Grade 13 Students Registered in First Year

\begin{tabular}{lllllll}
\hline & $1972-73$ & $1971-72$ & $1970-71$ & $1969-70$ & $1968-69$ & $1967-68$ \\
\hline $75-100 \%$ & $21.0 \%$ & $23.1 \%$ & $27.9 \%$ & $21.3 \%$ & $26.3 \%$ & $23.2 \%$ \\
$66-74 \%$ & $34.1 \%$ & $53.2 \%$ & $36.8 \%$ & $39.3 \%$ & $41.0 \%$ & $35.2 \%$ \\
$60-65 \%$ & $31.2 \%$ & $23.7 \%$ & $35.1 \%$ & $39.3 \%$ & $32.7 \%$ & $37.6 \%$ \\
$49-59 \%$ & $13.7 \%$ & & & & & \\
\hline
\end{tabular}

\section{Sex Distribution}

There was an almost equal ratio of males to females in the class which was similar to previous experience at the university.

The percentage of students receiving financial assistance under the Ontario Government's plan and the amount is shown in Table 2. A chi-square analysis indicated the percentage of awards for each group was not significantly different thus the method of admission appears to be essentially unrelated to the number or size of student awards.

Table 2

Percentage of Students Receiving Government Financial Assistance and the Average Size of the Awards

\begin{tabular}{ccccc} 
Group & \multicolumn{2}{c}{ Male } & \multicolumn{2}{c}{ Female } \\
& $\%$ & mean awards $\$$ & $\%$ & mean awards $\$$ \\
1 & 49.0 & 1250 & 40.9 & 1190 \\
2 & 51.8 & 1151 & 33.3 & 1154 \\
3 & 38.9 & 1213 & 44.7 & 849 \\
4 & 40.0 & 1214 & 40.0 & 1028 \\
5 & 30.2 & 998 & 34.2 & 1268 \\
6 & 32.6 & 1172 & 40.0 & 1217
\end{tabular}


The Grade 13 grades and SACU scores for the groups are shown in Table 3.

Table 3

Grade 13 Averages and SACU Mean Scores for Groups 1-6

\begin{tabular}{|c|c|c|c|c|c|c|}
\hline & \multicolumn{6}{|c|}{ Group } \\
\hline & 1 & 2 & 3 & 4 & 5 & 6 \\
\hline Grade 13 & 64.2 & 66.7 & 68.7 & 70.4 & 65.5 & 70.0 \\
\hline $\mathrm{SD}$ & 10.1 & 8.9 & 8.5 & 7.0 & 9.5 & 6.7 \\
\hline SACU Verbal & 508 & 542 & 541 & 543 & 555 & 543 \\
\hline SD & 107.5 & 99.8 & 87.0 & 98.6 & 87.8 & 98.2 \\
\hline \multirow[t]{2}{*}{ Math } & 459 & 457 & 482 & 479 & 475 & 457 \\
\hline & 108.7 & 101.9 & 103.0 & 106.9 & 89.7 & 123.5 \\
\hline
\end{tabular}

\section{Attitude Questionnaire Results}

The percentage of students in each of the admission groups who returned completed attitude questionnaires was $58.2,65.7,65.8,52.7,54.1$, and 56.3 for group 1 to 6 , respectively. In order not to jeopardize the study no effort was made to increase the return rate.

The attitude questionnaire data is summarized below (see Table 4). This data represents attitudes which the incoming class held prior to entry to the university. Analyses of variance showed that the groups did not differ significantly on any of the attitude scales ( $p>$ $.05)$.

Inspection of the data reveals that the students as a group tended to portray themselves as being favourable to less strict school practices, a slightly positive attitude towards education as an ideal, a slightly negative attitude towards the pragmatic use of education to man and a negative attitude towards teachers in high school. On the whole the group means of the groups were close to the theoretical mid-points of the education scales.

As a group the $S$ s described themselves as holding liberal views in regard to political, economic, religious, social and aesthetic cultural factors.

\section{Interview and Withdrawals}

A statistical analysis (chi-squares of individual items) of the responses to the structured interview revealed that the groups were not distinguishable in their endorsement of the items tested.

Table 5 shows the number of students who withdrew from the university, changed to part-time status or who completed the year. Withdrawal rates were markedly similar across groups. 
Table 4

Summary of the Attitude Questionnaire Date Showing the Mean Scale

Values for Each Group as Well as the Theoretical Mid Point for Each

Scale and the End Values

\begin{tabular}{lllllllllll}
\hline Name & \multicolumn{3}{c}{ Scales } & \multicolumn{7}{c}{ Group Mean } \\
& $\begin{array}{l}\text { Mid } \\
\text { Point }\end{array}$ & $\begin{array}{l}\text { Upper } \\
\text { Limit }\end{array}$ & Lower & & & & & & \\
& Limit & 1 & 2 & 3 & 4 & 5 & 6 \\
\hline $\begin{array}{l}\text { Attitude towards } \\
\begin{array}{l}\text { Education } \\
\text { Exhibit 3-14 }\end{array}\end{array}$ & 0 & 15 & -15 & -1.60 & -1.33 & -1.5 & -1.55 & -1.86 & -1.69 \\
\hline $\begin{array}{l}\text { Attitude towards } \\
\text { Education } \\
\text { Exhibit 6-2 }\end{array}$ & 5.85 & 11.4 & 0.3 & 3.33 & 3.59 & 3.48 & 3.41 & 3.33 & 3.33 \\
\hline
\end{tabular}

The Education

$\begin{array}{llllllllll}\text { Scale } & 65 & 11.0 & 20 & 56.8 & 58.6 & 55.6 & 55.4 & 59.5 & 56.5\end{array}$

Exhibit 6-1

Semantic distance

$\begin{array}{llllllllll}\text { Questionnaire } & 108 & 180 & 36 & 111.1 & 109.4 & 109.9 & 106.4 & 110.9 & 112.1\end{array}$

Exhibit 10-1

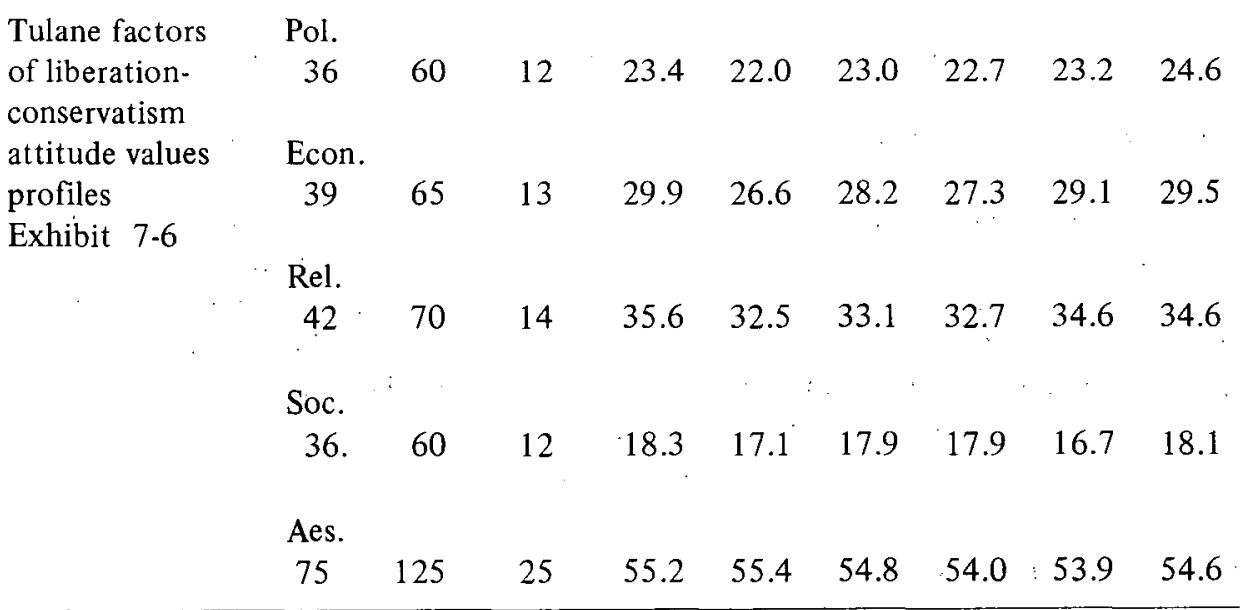

Exhibit 3-14 - score less than the mid-point indicates a favourable attitude to less strict school practices; Exhibit 6-2 - scores less than the mid-point indicate a positive attitude; Exhibit 6-1 - scores less than the mid-point equal a negative attitude; Exhibit 10-1 scores less than the mid-point equal a positive attitude; Exhibit 7-6 - scores less than the mid-point equal a liberal attitude. 
Table 5

\section{Distribution by Sex of Students Completing First Year, Withdrawing or Changing to Part-Time Studies}

\begin{tabular}{|c|c|c|c|c|c|c|c|c|c|}
\hline \multirow[b]{2}{*}{ Group } & \multicolumn{3}{|c|}{ Complete Year } & \multicolumn{3}{|c|}{ Withdraw } & \multicolumn{3}{|c|}{ Part-time } \\
\hline & M & $\mathrm{F}$ & Total & M & $\mathrm{F}$ & Total & $M$ & $\mathrm{~F}$ & Total \\
\hline 1 & 42 & 44 & 86 & 6 & 0 & $.6(6.4 \%)$ & 1 & 0 & 1 \\
\hline 2 & 50 & 39 & 89 & 4 & 3 & $7(7.3 \%)$ & 0 & 0 & 0 \\
\hline 3 & 33 & 35 & 68 & 3 & 2 & $5(6.8 \%)$ & 0 & 1 & 1 \\
\hline 4 & 42 & 52 & 94 & 7 & 3 & $10(9.5 \%)$ & 1 & 0 & 1 \\
\hline 5 & 47 & 35 & 82 & 4 & 2 & $6(6.6 \%)$ & 2 & 1 & 3 \\
\hline 6 & 45 & 44 & 89 & 4 & 5 & $9(9.1 \%)$ & 0 & 1 & 1 \\
\hline Totals & 259 & 249 & 508 & 28 & 15 & 43 & 4 & 3 & 7 \\
\hline
\end{tabular}

Final and interim Grade 13 averages for students withdrawing are shown in Table 6.

Table 6

Mean Grade 13 Averages for Students Withdrawing from the University

\begin{tabular}{cccccccc}
\hline & \multicolumn{3}{c}{ Male } & & \multicolumn{3}{c}{ Female } \\
\cline { 2 - 4 } \cline { 5 - 7 } Group & $\mathrm{N}$ & Interim & Final & & $\mathrm{N}$ & Interim & Final \\
\cline { 2 - 5 } 1 & 6 & 58.7 & 58.7 & & 0 & 0 & 0 \\
2 & 4 & 60.4 & 57.1 & & 3 & 71.8 & 72.5 \\
3 & 3 & 63.7 & 63.7 & & 2 & 72.6 & 70.3 \\
4 & 7 & 71.6 & 68.8 & & 3 & 71.0 & 70.8 \\
5 & 4 & 61.8 & 61.4 & & 2 & 69.3 & 72.5 \\
6 & 4 & 69.5 & 67.3 & & 5 & 71.2 & 72.2 \\
\hline
\end{tabular}

The higher marks for females is typical of the class as a whole. Seven of the male students and one of the female students had an interim Grade 13 average of under $60 \%$ :

Responses on the questionnaire completed by students withdrawing were compared with responses given in the interview by students who completed the year. Although:" 
the reasons for withdrawing were highly individual, as a group they responded consistently differently in several areas. A statistically significantly larger proportion of students (chi-square analysis) who withdrew reported that they had not made the right course selection and that they had been under some form of pressure to come to university. They also reported significantly more often that they felt that the lectures were not a satisfactory learning system for them and that the university was a community of social cliques.

A small number of students went to part-time status. The mean interim Grade 13 averages for the 4 males and 3 females who did so were 59.0 and $66.2 \%$, respectively. The mean final Grade 13 averages were 59.6 and $67.0 \%$, respectively. Their mean grade point averages in the courses they continued on a part-time basis were 1.5 and $1.6 \%$.

\section{Personality Test Data}

Table 7 shows the group membership on sex distribution of the students who completed the Adjective Check List.

Table 7

\section{Group Membership and Sex of Students Completing the Adjective Check List}

\section{Group}

$\begin{array}{lccccc}1 & 2 & 3 & 4 & 5 & 6 \\ (40 \%) & 26(54 \%) & 22(47 \%) & 23(48 \%) & 27(57 \%) & 19(46 \%) \\ (60 \%) & 22(46 \%) & 25(53 \%) & 25(52 \%) & 20(43 \%) & 22(54 \%)\end{array}$

The mean profiles for males and for females are shown in Table 8 .

Table 8

Mean ACL Scores for Males and Females

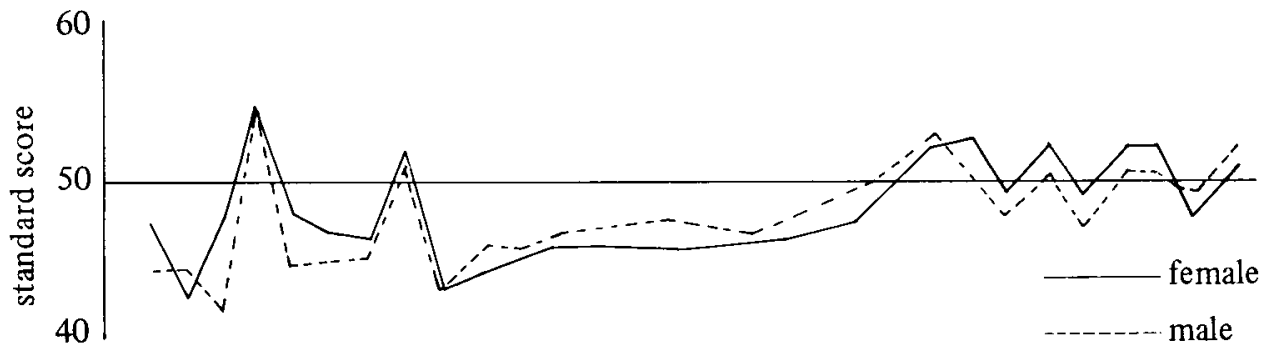


The 24 personality scales were analysed in $2 \times 6$ analyses of variance. No differences between groups and no significant interactions were found for any of the scales. A significant difference between sexes was found for some scales, i.e., Number adjectives checked, Favourable adjectives checked, Self-Confidence, Affiliation, Change and Counselling Readiness.

\section{Academic Success}

Table 9 shows the mean G.P.A. by group and sex for students who completed the year.

Table 9

Mean Grade Point Averages for Students Completing the Year

\begin{tabular}{lcccccc} 
& \multicolumn{7}{c}{ Group } \\
\cline { 2 - 7 } & 1 & 2 & 3 & 4 & 5 & 6 \\
Male & 2.02 & 2.03 & 2.05 & 2.20 & 1.91 & 1.85 \\
Female & 2.02 & 2.45 & 2.26 & 2.42 & 2.29 & 2.13 \\
\hline
\end{tabular}

A $2 \times 6$ analysis of variance failed to show any significant differences between experimental groups. A significant difference between sexes was found ( $F=11.77$ with 1 , 496 d.f. $p<.01$ ). The interaction failed to reach significance.

The distribution of students into success categories who completed the year is summarized on Table 10.

Table 10

Percentage of Students Who Completed the Year

Who Fall into Each Success Category

C.S.D.

\begin{tabular}{cccccccc} 
Group & \multicolumn{2}{c}{ Clear Success } & \multicolumn{2}{c}{ Probation } & \multicolumn{2}{c}{ Rustication } \\
& Male & Female & Male & Female & Male & Female \\
1 & 81.0 & 93.2 & 7.1 & 4.5 & 11.9 & 2.3 \\
2 & 82.0 & 92.3 & 16.0 & 5.1 & 2.0 & 2.6 \\
3 & 84.8 & 85.7 & 6.1 & 5.7 & 9.1 & 8.6 \\
4 & 90.5 & 96.2 & 7.1 & 1.9 & 2.4 & 1.9 \\
5 & 80.8 & 94.3 & 4.2 & 0 & 14.9 & 5.7 \\
6 & 68.9 & 81.8 & 8.9 & 11.4 & 22.2 & 6.8 \\
\hline
\end{tabular}


From inspection of the table there are clear sex differences with females experiencing fewer probation or rustication difficulties. These data were not analysed statistically because of the small cell frequencies in some categories. It appears, however, that slightly more people in the group selected on the basis of traditional methods experienced probation and/or rustication problems.

\section{Correlates of Success Within Each Group}

It was of interest to note the correlations of academic success within each group to ensure the data reported in the present study was similar to results reported previously (e.g., Atkinson, 1957-67). By and large low, but in some cases significant, correlations were reported for Grade 13 marks, SACU scores, teacher recommendations and personality test results with final first year GPA standings.

Breaking down these correlations for differences based on sex indicated a tendency for females to produce, on the whole, slightly higher correlations between selection criteria and first year GPA standings.

However, it should be noted, of all correlations recorded the highest predictive validity reported was (Grade 13 marks, females only with first year GPA) .63 accounting for only $40 \%$ of the variance.

\section{Project Admissions}

Of particular interest was the performance of those students who were admitted with a Grade 13 average of under $60 \%$ or over $60 \%$ who failed at least one Grade 13 credit. Both these types of students would not normally qualify for university admission. These were found primarily in the open admission and SACU groups, but some were also found in the interview and teacher recommendation groups.

Students with Grade 13 50: Six clear successes and one rustication were found for this group.

Students with Grade $1355 \quad$ 50: Seventeen clear successes, 4 probations and 6 rustications.

Students with Grade $1360 \quad$ 55: Thirty-four clear successes, 3 probations, and 7 rustications.

Students with a Grade 1360 and one or more failures: Seventeen clear successes, 2 probationary and 4 rustications.

In summary, these groups combined produced 74 clear successes, 9 probations, and 18 rustications. Thus, the percentage of clear successes was $73 \%$, probations $9 \%$, and rustications $19 \%$.

\section{DISCUSSION}

In this study the research group selected approximately $80 \%$ of the freshman year. The danger in such large scale "within house" applied studies is that the research procedures themselves, for a number of reasons, may produce a student sample unlike that usually found in the university. However, in this study the characteristics of the $1972-73$ class were similar to previous years in terms of Grade 13 distribution of 
marks and geographical distribution. Also the five project admissions groups were similar to the university's traditional admission group as to male-female ratio, amount of financial assistance granted to attend university, attitudes towards education, liberalconservative dimensions of political, economic, religious, societal and aesthetic views, and personality as defined by the Adjective Check List.

Another check on the validity of the data gathered comes in respect to obtaining data that has been typically found in university studies of this type. That is, sex differences should be related to academic achievement. Females usually demonstrate better achievement and in this study they obtained higher grade point averages than males and also had lower withdrawal, probation, and rustication rates. Secondly, the data in the study should conform to other studies in that various individual differences should correlate somewhat with academic achievement. In this study as in previous reports (Atkinson, 1957-67), significant correlations were reported for Grade 13 marks, SACU test scores, teacher recommendations, and personality test results with final first year GPA standings. As many others have found, these correlations, while in some cases significant, were quite low, thus being of very little predictive value. Also, females, on the average, produced slightly better predictive validities of first year GPA standings.

Thus, with the exception of the project admission students who had Grade 13 averages less than $60 \%$, the selection criteria produced groups that differed primarily only as to the method of selection and had characteristics in keeping with traditional university admission policies.

\section{Effects of the Selection Procedures}

In examining the effectiveness of admissions procedures in encouraging students to enroll in university, there was little question that the interview technique was the most efficacious outreach device. Compared to the other methods of admission, the interview technique produced a ten percent higher confirmation rate.

The reasons for withdrawal included the following: course selection, family pressures to come to university, perceived social cliques within the university, and dislike of the lecture portion of the system. These reasons for withdrawal conformed to data from past years gathered by the Health Service in the university in which the study was conducted. It was found that the open admissions groups yielded a lower percentage of withdrawals. The percentage of withdrawals across selection procedures ranged from. $6.4 \%-9.5 \%$. In examining the probation and rustication information (Table 10) the data indicated that generally the highest probation and rustication rates were for the traditional university method of admission. The group selected on the basis of Grade 13 interim marks had the lowest probation and rustication rates. However, it should be noted that this data reflects only trends. Because of very few cell-frequencies in some categories a frequency distribution statistical analysis was not appropriate.

The group obtaining the lowest grade point average was that admitted by traditional university procedures. For males the group yielding the best grade point average was that selected on the basis of interim Grade 13 marks and for females the group obtaining the best grade point average was the group selected using the interview technique. Again it must be emphasized these are only trends for a statistical analysis of this data indicated no over-all significant statistical effect in the comparison of GPA across groups. 
Of particular interest is the fact that the open admission group, the one which included students who were not normally qualified for university admission, compared quite favourably with the other admissions procedures in terms of GPA.

\section{Implications of the Study}

The increased acceptance rate of applicants to the University who were interviewed has important implications for universities. The interview process may be regarded by some critics as a successful method of inducing students to attend a particular institution through a personalized form of salesmanship. The interview may indeed be utilized in such a fashion but to attribute a greatly increased response rate to such tactics is to assume a body of applicants who are not discriminating and are very easily manipulated. Experience of the interviewers in this project does not confirm such a conclusion. The increased acceptance rate in the interview group may be more realistically attributed to a desire among university applicants for direct and personal channels of communication to the university. Although universities direct a good deal of their resources to the production of informative brochures and pamphlets for applicants the experience of the project researchers is that this method is not as successful as many university officials would hope or expect. A face-to-face interview with a representative of a university also tends to break down the corporate and bureaucratic image which most universities have acquired in the eyes of students especially since the advent of the Ontario Universities Application Centre.

The most significant research finding centred on the performance of the open admission group. The argument against open admission is that the students most likely to benefit from university education are those who have certain Grade 13 academic qualifications. The assumption is that these students are likely to prove to be the most "satisfactory" to the university with satisfaction operationally defined in terms of academic achievement. The idea of an open admission concept or admitting students who, while they qualify on other grounds, do not have satisfactory Grade 13 performance has long been avoided by university admissions offices. These types of students are supposedly "unqualified" and would presumably undermine academic standards.

In fact, the open admissions group in the present study produced a final first year GPA average well in line with other admissions groups. Secondly, their withdrawal, probation and rustication rates were very similar to those of the other admissions groups. The group selected on the basis of Grade 13 marks produced a relatively high average GPA and also had relatively few probations and rustications. Nevertheless, the statistical analysis of the data indicated no statistically reliable effect for the Grade 13 group compared to the open admissions group or any other group on these variables.

Furthermore, in the present study, the performance of all students who failed to meet the normal admission requirements employed by most Ontario Universities was examined. Eighty-one percent of this "unqualified" subgroup successfully completed their first year of university. It's unlikely any university could or would justify an admissions policy which eliminates a group of students, most of whom would succeed in their program of studies. The authors are well aware that any single study in a particular university may be somewhat limited in its generalization. Nevertheless the very high percentage rate of successful completions of the academic year by this sub- 
group and also by the open admissions group gives pause for serious reflection regarding traditional admission procedures and the human cost factor involved.

No value can be applied to a human cost factor but the authors would argue that there could even be situations where an "unqualified" group which had a 50\% or lower success rate would qualify for university education. The authors' experience with universities which operate on a true open admissions basis, e.g., Hunter College of City University of New York, indicates that such universities operate on a much higher failure rate for open admissions policies and yet find it fruitful to continue this educational process in terms of its value to society.

It might be argued that our selection procedures were not "select" enough. This argument has a number of problems. Taking this argument to its logical extension, the only sure method of eliminating failures is to admit no students. Existing data indicates that correlations between Grade 13 and other selection criteria with first year academic performance are not high enough to be of any practical use. In this study, upon analysing the data, we took note of the extremes of the selection procedures. If we focused on, for example, the top $10 \%$ or $20 \%$ of the students selected in the Grade 13 category we still came across students who produced poor final GPA's and had probations, rustications and withdrawals. By being highly selective and literally "picking our" data the best correlation we could come up with in regard to Grade 13 marks and final first year GPA average was that for females only and then accounting for only $40 \%$ of the variance.

In this study the group admitted by traditional university procedures had a relatively higher probation and rustication rate than other groups. Also the final first year average GPA for this group was slightly lower than in the other groups. This result may have been an anomaly or possibly may reflect on the fact that one definite type of admissions procedure involves slightly less human cost than one which is based on a multitude of unquantified and intuitive admissions criteria. Of course the open admissions group was not based on any criteria (even less than the traditional procedure which relies a fair amount on Grade 13 marks) but in this group's case students may have realized that they were being offered an opportunity normally denied them and decided to make the most of it.

The authors have noted above the difficulties in generalizing from any one study. The university in question is not identical to other universities in Ontario. On the other hand it would be difficult to argue that the instructional methods, administrative structure, and nature of students and staff at the University studied were substantially different from any other university in Ontario. This study focused on Arts and Science students and indeed this body of students still forms the largest percentage of students enrolled in Ontario universities. Thus the authors would argue that it is somewhat unlikely the results gained in the present study do not bear consideration by other institutions.

The research was supported by grant $3 D U A 18$ from the Ontario Ministry of Colleges and Universities. The support given to the research group by colleagues, Mr. Alf Cole, Registrar and the then Dean, T.E.W. Nind was greatly appreciated. We are particularly indebted to Ms. Edythe Parkinson, Research Associate primarily responsible for the 
16 Gordon Pollock, et al.

gathering and analysis of data and to Ms. Deborah Worrad for her valued service as interviewer on the project. Alex Bird and Joan Knowles also contributed to the project.

Research requests should be addressed to the Office of the Registrar, Trent University, Peterborough, Ontario K9J 788.

\section{References}

Boronkay, F.Y. "Study of Natural Sciences 1970-71; Study of Social Sciences 1970-71; Study of Humanities 1970-71; Study of Business I 1970-71," (McMaster University, 1972.)

Fleming, W.G., et al, Atkinson Study of Utilization of Student Resources, Volume 1-13 (Toronto, 1957 to 1967$)$.

Gough, H.G. and Heilbrun, A.B. The Adjective Check List Manual. Palo Alto, California: Consulting Psychology Press, 1965.

Shaw, M.E. and Wright, J.M. Scales for the Measurement of Attitudes. New York: McGraw-Hill, 1967. 